\title{
Comparison of students' performance of objective structured clinical examination during clinical practice
}

\author{
Jihye $\mathrm{Yu}^{1}$, Sukyung Lee ${ }^{2}$, Miran $\mathrm{Kim}^{1}$ and Janghoon $\mathrm{Lee}^{2}$ \\ ${ }^{1}$ Office of Medical Education and ${ }^{2}$ Ajou Center for Clinical Excellence, Ajou University School of Medicine, Suwon, \\ Korea
}

Purpose: Clinical practice for medical students aims to improve their clinical competency. Since students gain experience in clinical practice, it is assumed that their capacity for care is strengthened. This study aimed to verify whether there is a change in the competency of medical students after clinical practice.

Methods: We assessed the clinical performance of 120 medical students who were enrolled in the fifth year over the academic years 2016-2018. Objective structured clinical examination (OSCE) was used to measure the clinical competency.

Results: The OSCE scores for November fifth grade improved significantly compared to May fifth grade. The scores in September of sixth grade were slightly lower than those of November of fifth grade, but there was no statistically significant difference.

Conclusion: It was confirmed that the clinical practice of fifth-year students improved their clinical competency, but it did not show any significant shift in the clinical competency of sixth-year students. The results of this study suggest that it is very important to organize the curriculum so that students can continue to experience patient-facing care throughout the entire clinical practice course to produce highly qualified physicians.

Key Words: Medical student, Clinical practice, Assessment, Clinical competence, Objective structured clinical examination

\section{Introduction}

The clinical practice course in medical education aims to train students to have appropriate medical competency for medical care [1]. In clinical practice, students learn clinical diagnosis, clinical skills, and ways to interact with patients as doctors. Patient encounter is the most important part of clinical practice to improve a student's clinical competency [2].

Clinical experience during clinical practice varies from student to student. Clinical experience can be defined as the student's experience in clinical settings, including bedside small-group tutorials, ward round, patient preconsultation, attendance at operations, seeing or learning special procedures, and clinical or paramedical case conference [3]. The study analyzing the relationship between clinical experience and subsequent performance of the students shows mixed results. Previous studies have shown that a greater amount of clinical experience does not necessarily result in good subsequent clinical performance [3], while experiences with real patients
Received: March 11, 2020 • Revised: April 20, 2020 • Accepted: May 25, 2020 Corresponding Author: Janghoon Lee (https://orcid.org/0000-0003-4765-9948) Ajou University School of Medicine, 164 World cup-ro, Yeongtong-gu, Suwon 16499, Korea Tel: +82.31.219.5169 Fax: +82.31.219.5169 email: neopedlee@aumc.ac.kr
Korean J Med Educ 2020 Sep; 32(3): 231-235.

https://doi.org/10.3946/kjme.2020.168

eISSN: 2005-7288

(C) The Korean Society of Medical Education. All rights reserved. This is an open-access article distributed under the terms of the Creative Commons Attribution Non-Commercial License (http:// creativecommons.org/licenses/by-nc/3.0/), which permits unrestricted non-commercial use, distribution, and reproduction in any medium, provided the original work is properly cited. 
may improve clinical competency [4]. However, the number of patient encounters does not necessarily guarantee clinical competency $[5,6]$.

Clinical competency is based on clinical skill, scientific knowledge, and ethical attributes required in clinical settings [7]. The clinical competency of medical students is important in that it affects clinical performance as a doctor after graduation [8]. Measurement of clinical competency can be done through the assessment of the clinical competency of students who have gone through the clinical practice course.

Therefore, the purpose of this study is to compare the student's performance of objective structured clinical examination (OSCE) before and after clinical experience.

\section{Methods}

\section{Data collection}

The course curriculum of Ajou University School of Medicine covers a total of 6 years: 2 years of premedical, 2 years of preclinical, and 2 years of clinical training. The structure of the clinical practice process is presented in Table 1. The fifth-year clinical practice consists of internal medicine, general surgery, obstetrics and gynecology, pediatrics, and psychiatry, which runs from mid-February to November. The sixth-year runs from mid-January to the end of July, and has required courses in emergency medicine, traumatology, community medi-

\begin{tabular}{|c|c|c|}
\hline Year & Course (times of preliminary medical examination trials)/term & Objective structured clinical examination \\
\hline \multirow[t]{5}{*}{ Fifth year } & Internal medicine ${ }^{\text {al }}$ (10 or more times)/14 weeks & Nephrology (two cases) \\
\hline & General surgery ${ }^{a}(1$ or more times $) / 5$ weeks & Obstetrics and gynaecology (three cases) \\
\hline & Obstetrics \& gynaecology ${ }^{\text {al }}(1$ or more times $) / 5$ weeks & Pediatrics (three cases) \\
\hline & Pediatrics $^{\text {al }}(5$ times $) / 5$ weeks & Psychiatry (two cases) \\
\hline & Psychiatry/5 weeks & \\
\hline \multicolumn{3}{|l|}{ Sixth year } \\
\hline \multirow[t]{11}{*}{ Required courses } & Emergency medicine/2weeks & Orthopaedics (two cases) \\
\hline & Traumatology/2 weeks & \\
\hline & Community medicine/2 weeks & \\
\hline & Radiology/2 weeks & \\
\hline & Neurology ${ }^{\text {al }}(1$ time $/ 2$ weeks & \\
\hline & Family medicine ${ }^{\text {a) }}(1$ time $/ 2$ weeks & \\
\hline & Orthopaedics/2 weeks & \\
\hline & Dermatology $y^{a}$ (1 or more times)/2 weeks & \\
\hline & Urologya) (1 time)/1 week & \\
\hline & Ophthalmology ${ }^{\text {al }}$ (1 or more times)/1 week & \\
\hline & Otolaryngology/2 weeks & \\
\hline \multirow[t]{9}{*}{ Electives (six choices) } & Nuclear medicine/2 weeks & \\
\hline & Radiation oncology/2 weeks & \\
\hline & Physical medicine and rehabilitation/2 weeks & \\
\hline & Occupational and environmental medicine/2 weeks & \\
\hline & Neurosurgery/2 weeks & \\
\hline & Thoracic and cardiovascular surgery/2 weeks & \\
\hline & Plastic surgery/1 week & \\
\hline & Anaesthesiology/2 weeks & \\
\hline & Clinical pathology/1 week & \\
\hline
\end{tabular}

\footnotetext{
${ }^{\text {a) }}$ Practice in preliminary medical examination of the outpatient.
} 
cine, radiology, neurology, family medicine, orthopedics, dermatology, urology, ophthalmology, and otorhinolaryngology, and other elective courses.

In this study, OSCE scores of 120 students who attended fifth and sixth-year in Ajou University School of Medicine in the years 2016-2017, 2017-2018, 20182019 were collected and analyzed. The subject distribution is shown in Table 2. The assessment was conducted at the end of May for fifth-year students (at $1 / 3 r d$ phase of the practice), at the end of fifth-year, and at the end of sixth-year.

\section{Outcome measures}

OSCE is highly valid for testing and has become a strong indicator of good performance [9]. The OSCE is known as 'clinical performance examination (CPX)' in Korea. The OSCE scenario used in this study was developed by the Seoul-Gyeonggi CPX Consortium. It involved examining three cases in May and six cases in November for fifth-year students, and six cases in September for sixth-year students. Each student was

Table 2. Characteristics of Study Participants

\begin{tabular}{lc}
\hline \multicolumn{1}{c}{ Variable } & No. $(\%)$ \\
\hline Gender & \\
Male & $76(63.3)$ \\
Female & $44(36.7)$ \\
Period of clinical practice & \\
$2016-2017$ & $43(35.8)$ \\
$2017-2018$ & $40(33.3)$ \\
$2018-2019$ & $37(30.8)$ \\
\hline
\end{tabular}

given a total of 16 minutes, consisting of 1 minute of case introduction, 10 minutes of patient treatment, and 5 minutes of high-probability diagnosis and planning. The OSCE score is the combined score of history taking, physical examination, interpersonal interactions with standardized patient scores, and assessment hypotheses and planning.

\section{Analysis}

Descriptive statistical analysis was conducted to examine the distribution of study subjects. Paired t-tests were conducted to analyze the changes in OSCE scores at 3-time points in clinical practice.

\section{Compliance with ethical standards}

This study was approved by the Institutional Review Board of Ajou University Hospital (ethics consent no., AJIRB-SBR-SUR-19-442). It proceeded with consent exemption.

\section{Results}

Table 3 shows that the OSCE scores for three periods increased during fifth year, but did not show a significant change after the sixth grade. As a result of analysis by sub-factor, history taking did not change during the fifth and sixth grades, and physical examination and patient-physician interaction increased

Table 3. Characteristics of Study Participants

\begin{tabular}{|c|c|c|c|}
\hline \multirow{2}{*}{ OSCE $(n=120)$} & \multicolumn{3}{|c|}{ Assessment time } \\
\hline & May/fifth year & November/fifth year & September/sixth year \\
\hline Total $^{\text {al }}$ & $54.94 \pm 6.25$ & $59.69 \pm 5.55$ & $59.35 \pm 7.06$ \\
\hline History-taking & $64.24 \pm 8.38$ & $65.02 \pm 7.34$ & $65.68 \pm 9.09$ \\
\hline Physical examination ${ }^{\text {al }}$ & $39.71 \pm 11.75$ & $49.79 \pm 11.26$ & $47.96 \pm 11.53$ \\
\hline Patient-physician interaction ${ }^{\mathrm{al}}$ & $60.87 \pm 5.73$ & $64.24 \pm 5.41$ & $64.42 \pm 6.70$ \\
\hline
\end{tabular}

Data are presented as mean \pm standard deviation.

OSCE: Objective structured clinical examination.

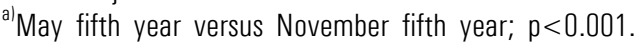


during the fifth grade, but there was no significant change after the sixth grade.

\section{Discussion}

An analysis of the OCSE scores of medical students showed that the level of clinical competency of students after fifth year clinical practice increased significantly, but the clinical competency after sixth year clinical practice did not vary significantly, when compared to the end of the fifth year. This is in contrast to previous studies, which showed that as the years increase, the achievement level in clinical performance increases [10]. Although the case is different for each test in OSCE used in this study, it can be inferred that score variation according to the case is not large because the average score of all subjects does not differ significantly from test to test. We found that increasing the amount of clinical practice experience do not necessarily improve clinical competency.

In clinical practice in the fifth year, students conduct pre-consultation, write a patient medical record, and develop a diagnosis and treatment plan by taking the history of the patient and conduct physical examinations of outpatients. And students are assigned to serve as primary care physicians for inpatients and brief them at the case conference. Students also conduct clinical performance for standardized patients. Clinical skill training using simulated patients has a positive effect on improving students' clinical competency [11].

On the other hand, the sixth-grade practice focuses on mastering the specialized knowledge and skills required in each clinic and developing basic skills to be a physician. Compared to the fifth year, the opportunities for patient encounters are relatively low for the students. Such differences in the composition of the practice may have influenced the students' ability to perform clinical practice such as physical examination and patientphysician interaction. Meeting a sufficient number of patients is essential for improving clinical competency [2]. Gathering relevant information from patients, considering it comprehensively, establishing a diagnostic hypothesis, and making decisions are very important activities in clinical practice [6]. Clinical practice courses should be structured in such a way as to enable students to fully experience the patient-facing situation, so that they become doctors with clinical competency in primary care settings. Also, the number of OSCE experiences is much less than in the fifth grade. OSCE can be a valuable method to improve students' clinical performance [12].

The findings of this study have implication in that it has been confirmed that the composition of the clerkship course is important for the continuous development of patient care competency of medical students. This study confirmed that it is important to construct a clerkship course so that students can have a patient encounter experience evenly during the clinical practice period in order to ensure for students to be competent in history taking, physical examination, and interaction with patient.

Nevertheless, this study has a limitation in that it lacks a detailed analysis of the contents of the students' clinical experience, including patient-facing experience, instructors' supervision or feedback, and so forth. Subsequent studies will need to explore these details of clinical practice as variables and analyze in detail how these variables affect the clinical performance of medical students.

It is very important to organize the curriculum so that students can continue to experience patient-facing care throughout the entire clinical practice course to produce highly qualified physicians. It is necessary to reflect this in clinical department placement and content com- 
position. If it is practically difficult to provide an opportunity to see a real patient, it will be necessary to provide a variety of educational experiences such as training using standardized patients or simulators.

\section{ORCID:}

Jihye Yu: https://orcid.org/0000-0002-8039-6580;

Sukyung Lee: https://orcid.org/0000-0003-1747-8329;

Miran Kim: https://orcid.org/0000-0001-5553-5334;

Janghoon Lee: https://orcid.org/0000-0003-4765-9948

Acknowledgements: None.

Funding: None.

Conflicts of interest: No potential conflict of interest relevant to this article was reported.

Author contributions: YJH, LSK, KMR, and LJH conceived the study concept and design; YJH analyzed and interpreted the data, draft the manuscript; KMR reviewed and revised the manuscript; and LJH critically revised the manuscript and supervised the study.

\section{References}

1. Kramer AW, Jansen JJ, Zuithoff P, et al. Predictive validity of a written knowledge test of skills for an OSCE in postgraduate training for general practice. Med Educ. 2002;36(9):812-819.

2. Snell LM, Battles JB, Bedford JA, Washington ET. Verifying the curriculum of a family medicine clerkship. Med Educ. 1998;32(4):370-375.

3. Jolly BC, Jones A, Dacre JE, Elzubeir M, Kopelman P, Hitman G. Relationships between students' clinical experiences in introductory clinical courses and their performances on an objective structured clinical examination (OSCE). Acad Med. 1996;71(8):909-916.
4. Rudaz A, Gut AM, Louis-Simonet M, Perrier A, Vu NV, Nendaz MR. Acquisition of clinical competence: added value of clerkship real-life contextual experience. Med Teach. 2013;35(2):e957-e962.

5. Ericsson KA. Deliberate practice and the acquisition and maintenance of expert performance in medicine and related domains. Acad Med. 2004;79(10 Suppl):S70S81.

6. Wimmers PF, Schmidt HG, Splinter TA. Influence of clerkship experiences on clinical competence. Med Educ. 2006; 40(5):450-458.

7. Epstein RM, Hundert EM. Defining and assessing professional competence. JAMA. 2002;287(2):226-235.

8. Wallenstein J, Heron S, Santen S, Shayne P, Ander D. A core competency-based objective structured clinical examination (OSCE) can predict future resident performance. Acad Emerg Med. 2010;17 Suppl 2:S67-S71.

9. Jefferies A, Simmons B, Tabak D, et al. Using an objective structured clinical examination (OSCE) to assess multiple physician competencies in postgraduate training. Med Teach. 2007;29(2-3):183-191.

10. Remmen R, Scherpbier A, van der Vleuten C, et al. Effectiveness of basic clinical skills training programmes: a cross-sectional comparison of four medical schools. Med Educ. 2001;35(2):121-128.

11. Taylor S, Haywood M, Shulruf B. Comparison of effect between simulated patient clinical skill training and student role play on objective structured clinical examination performance outcomes for medical students in Australia. J Educ Eval Health Prof. 2019;16:3.

12. Nagoshi Y, Cooper LA, Meyer L, et al. Application of an objective structured clinical examination to evaluate and monitor intern's proficiency of hand hygiene and personal protective equipment use in the United States. J Educ Eval Health Prof. 2019;16:31. 